RECENT ADVANCES

\title{
Hypotension in the very low birthweight infant: the old, the new, and the uncertain
}

\author{
S J Dasgupta, A B Gill
}

Hypotension occurs in up to $20 \%$ of very low birthweight infants, usually in the first 48 hours after birth. Its importance lies in its possible causal link with brain injury. Its management is controversial.

ש.......................

- very paediatrician working on a neonatal - unit will have treated the very low birthweight (VLBW; < 1500 g) infant with hypotension. Hypotension, however defined, occurs in up to $20 \%$ of VLBW infants, most commonly in the first 48 hours after birth. Its importance lies in its possible causal link with brain injury in these infants. ${ }^{1-4}$ The common dilemma is when to treat, and how.

There are numerous controversies surrounding the management of hypotension in the VLBW infant. Firstly, the definition of hypotension varies, particularly at the extremes of prematurity. Secondly, the method of monitoring blood pressure is also variable; in particular, the value of non-invasive assessment remains open to debate. Thirdly, the causes of hypotension and its effect on prognosis in these babies is not proven. Lastly, treatment remains prone to personal preference, as it has not been as extensively studied as one might expect.

This article reviews the definition of hypotension, its clinical relevance, and the available treatments, including volume support, inotropes, and steroids.

\section{DEFINITION}

Normal blood pressure has proved difficult to define in preterm babies, partly because it varies with gestational and postnatal age, ${ }^{56}$ but also because the range of blood pressure that will ensure adequate organ perfusion is not known. A few studies have attempted to define the normal range of blood pressure in the neonate. ${ }^{156-8}$ These have resulted in two widely accepted definitions of hypotension:

See end of article for authors' affiliations

....................

Correspondence to: Dr Gill, Peter Congdon Neonatal Unit, Leeds General Infirmary, Leeds LS2 9NS, UK;

bryan.gill@leedsth.nhs.uk

Accepted

21 December 2002

.................... the first definition, after the observation that the 10th centile for mean blood pressure is roughly equal to the gestational age. It is worth remembering, however, that this is only valid in the first 48 hours of life. ${ }^{5}$
Arch Dis Child Fetal Neonatal Ed 2003;88:F450-F454

\section{MEASUREMENT}

Monitoring of intra-arterial blood pressure through an umbilical or peripheral arterial catheter is widely accepted as the optimum method. Several studies have compared oscillometric with invasive measurement. Provided that cuff size is standardised, oscillometric measurement seems to be accurate within the normal range. ${ }^{9}{ }^{10}$ However, concern has been expressed that, at the lower levels, it consistently overestimates the blood pressure, providing false reassurance. ${ }^{11}$ We refer the reader to articles that have explored this issue in more detail. ${ }^{9-12}$

\section{CLINICAL RELEVANCE}

\section{Tissue perfusion}

In neonatology, blood pressure is regularly used as a marker of systemic organ perfusion. Unfortunately, there are few data to support this. Kluckow and Evans ${ }^{13}$ showed that there is only a weak correlation between blood pressure and cardiac output in preterm infants. Furthermore, as blood pressure is the function of blood flow and systemic vascular resistance, blood pressure may not reflect the blood flow in end organs, as the vascular resistance will vary. Several methods that may be useful for assessing systemic blood flow and tissue perfusion in neonates are being evaluated.

Left ventricular output is often used in adults to assess systemic blood flow. Measurements of ventricular outputs in neonates may be confounded by shunts through a patent ductus or foramen ovale. Kluckow and Evans ${ }^{14}$ successfully measured systemic blood flow in the superior vena cava of newborn infants, using Doppler echocardiography. Flow in the superior vena cava was chosen to represent blood flow in the upper body, particularly the brain, and correlated well with left ventricular output in babies with a closed duct.

Wardle et $a l^{15}$ used near infrared spectroscopy (NIRS) to measure haemoglobin flow and venous saturation in the forearm of hypotensive preterm babies. From this they were able to calculate oxygen delivery and consumption and fractional oxygen extraction. They found that peripheral oxygen delivery and consumption were lower in hypotensive babies, but that oxygen extraction was similar to normotensive controls. There was also no rise in lactate concentration. The results suggest that in hypotensive 
babies, peripheral oxygen delivery is still adequate for tissue demands, challenging the need to routinely correct hypotension. Tsuji et al ${ }^{16}$ used NIRS to monitor cerebral circulation in sick premature infants. They showed a direct relation between mean arterial blood pressure and cerebral intravascular oxygenation. However, in a further study by Wardle et al, ${ }^{17}$ there was no relation between hypotension and cerebral fractional oxygen extraction, suggesting that sufficient oxygen is delivered to meet demand even in the presence of hypotension.

As NIRS and cardiac output measurements are not continuous, their role in the decision to treat a blood pressure level remains unclear. They do, however, question our present practice of using a single value below which treatment should be started.

Gastric intramucosal pH (tonometry) has been measured as a reflection of gut perfusion, which may be of value in assessing overall tissue perfusion. Campbell et $a l^{18}$ showed a relation between gastric intramucosal $\mathrm{pH}$ and blood flow in the superior mesenteric artery of newborn piglets. In a study in VLBW infants, the same team also found that intramucosal $\mathrm{pH}$ was independently predictive of major gastrointestinal complications in VLBW infants. ${ }^{19}$ These results suggest that gastric tonometry may be a useful, relatively noninvasive method of evaluating tissue perfusion in preterm infants.

Further research in this area is obviously needed before techniques such as this have direct relevance to the management of hypotension. Until this is available, it would seem important that a blood pressure level should not be the only criterion in determining when to treat, and that other markers of systemic perfusion, such as metabolic acidosis, capillary refill time, urine output, and peripheral temperature should also be considered. These additional clinical parameters of cardiovascular status are not proven to be of value in determining end organ perfusion in newborn infants. ${ }^{20} 21$ However, at present they are the only easily repeatable additional assessments, and are used by many clinicians in deciding an individual patient's "hypotensive level".

\section{Cerebral injury}

It is well documented that sick VLBW infants have reduced cerebral vascular autoregulation compared with term infants, ${ }^{22}{ }^{23}$ with the postulated effect that severe hypotension may lead to cerebral hypoperfusion. Hypotension has been linked to cerebral haemorrhage and ischaemia in many studies. Watkins et al ${ }^{1}$ found that hypotension was strongly associated with intraventricular haemorrhage, but not with periventricular ischaemic lesions. Hypotension is thought to lead to intraventricular haemorrhage by causing ischaemic damage to the germinal matrix, which bleeds on reperfusion. It is unlikely that overenthusiastic correction of hypotension is involved, as episodes of hypertension in this study were not associated with the occurrence of intraventricular haemorrhage. A review of recent studies by Dammann et al $^{3}$ supports the finding of Watkins et al that systemic hypotension does not, in itself, lead to periventricular leucomalacia. There is also evidence to link episodes of hypotension in the neonatal period to long term neurological sequelae. In a study of 98 premature babies, Low et al ${ }^{4}$ found that sustained hypotension and hypoxaemia, in the first four days after delivery, increased the probability of a major adverse neurodevelopmental outcome from $8 \%$ to $53 \%$. Interestingly, there is little evidence to support the view that treating hypotension prevents these sequelae.

\section{MANAGEMENT}

The aim of treating hypotension is to preserve adequate organ perfusion and thus to prevent complications such as cerebral injury. However, a cause for hypotension should always be sought before treatment is instituted. Important conditions to exclude include:

- Blood loss

- Pneumothorax

- Sepsis

- Patent ductus arteriosus

- High positive intrathoracic pressure (secondary to mechanical ventilation)

- Heart failure

If one of the above causes is identified, the primary treatment of the hypotension is to institute the specific treatment for the underlying condition. In most instances, a cause for hypotension in the neonatal period will not be determined, although myocardial dysfunction has been identified as a common factor in, ${ }^{24}$ and treatment will be initiated on the basis of unit protocols. These normally follow a stepwise approach beginning with volume support followed by inotropes and, in some, the use of steroids.

\section{Volume support}

It is generally accepted that hypovolaemia is an uncommon cause of hypotension in the sick preterm infant. ${ }^{25}$ It is also difficult to diagnose in the immediate postnatal period, as indicators such as urine output and capillary refill time are unreliable. However, because it does occasionally occur, and is relatively easy to treat, most units adopt a policy of moderate volume replacement before the institution of inotropes.

Fluids available for volume replacement may be either crystalloid or colloid. The main difference between the two is the oncotic pressure effect, according to Starling's law, and the theoretical difference in the length of time they stay in the intravascular space.

Emery et $a l^{26}$ looked at the protein content of solutions used to treat hypotension, and found that volume appeared to be more important than protein content in producing a sustained increase in blood pressure. More recently, King et $a l^{27}$ showed that isotonic saline is as effective as $5 \%$ albumin for treating hypotension in preterm infants. Furthermore, they found an additional advantage, in that saline caused less fluid retention, in the first 48 hours of life, than albumin. This was thought to be due to the high capillary leak of plasma proteins into the interstitial space, resulting in interstitial oedema.

There are, of course, other advantages of crystalloid over colloid, which should be considered.

- Colloids are blood products and therefore carry an infection risk

- The cost of isotonic saline is about one-fiftieth of that of $4.5 \%$ human albumin solution

In summary, it seems that colloid and crystalloid are equally effective in treating hypotension in the neonatal period. Considering the other advantages of using isotonic saline, it would seem that the safest approach to volume replacement would be to use $10-20 \mathrm{ml} / \mathrm{kg} 0.9 \%$ saline given over 30 minutes in the first instance. The use of $4.5 \%$ albumin should be reserved for babies who are likely to be hypovolaemic secondary to protein-losing conditions, such as those who have had gastrointestinal surgery.

\section{Dopamine and dobutamine}

Most neonatal intensive care units support the use of dopamine and dobutamine as inotropic agents in the treatment of hypotension. Their use, however, is historically 
based rather than evidence based, and there are few data relating to associated mortality and morbidity.

There is evidence that myocardial dysfunction plays an important role in the development of hypotension in preterm infants in the first few hours of life. ${ }^{24}$ It is therefore clear that inotropic agents should be of some benefit in the management of hypotension in these babies.

In a study comparing early use of dopamine infusion to volume expansion with plasma protein fraction, Gill and Weindling ${ }^{28}$ showed that dopamine was more effective in restoring normal blood pressure. In fact, this study supported the initiation of treatment with dopamine without waiting for a response to volume expansion.

Dopamine is a sympathomimetic amine which exerts its cardiovascular effects through dopaminergic and $\alpha$ and $\beta$ adrenergic receptors. It is thought to exert up to $50 \%$ of its inotropic effect through an indirect action on $\beta_{2}$ adrenoceptors, stimulating the release of endogenous noradrenaline. ${ }^{29}$

There have been several studies into the pharmacokinetics and mechanism of action of dopamine in the preterm infant. Roze et $a l^{30}$ showed a dose dependent increase in mean arterial blood pressure with dopamine infusions of 5-20 $\mu \mathrm{g} /$ $\mathrm{kg} / \mathrm{min}$. The increase in blood pressure in this study was attributed to an increase in systemic vascular resistance, but not in left ventricular output. Padbury et $a l^{31}$ showed a dose dependent increase in myocardial contractility and resulting cardiac output at dopamine doses of $1-8 \mu \mathrm{g} / \mathrm{kg} / \mathrm{min}$, without significant changes in systemic vascular resistance or heart rate. Seri et al ${ }^{32}$ have shown that, at doses of $2.5-7.5 \mu \mathrm{g} / \mathrm{kg}$ / min, dopamine causes selective renal, but not mesenteric vasodilatation in preterm babies with an overall increase in total peripheral vascular resistance. There was no effect on cerebral blood flow at this dose. It is worth noting, however, that this study was carried out on normotensive neonates. Studies in adults suggest that, in sick hypotensive patients, there is a downregulation of adrenergic receptors, requiring much higher doses of dopamine to maintain blood pressure. ${ }^{33}$ However, there have been no such studies in neonates. There is also some suggestion that preterm infants have relative adrenal insufficiency. ${ }^{34}$ Further research is clearly required to define a maximum dose for dopamine, as the use of high doses $(>25 \mu \mathrm{g} / \mathrm{kg} / \mathrm{min}$ ) has not been studied.

Dobutamine is a relatively cardioselective sympathomimetic amine which exerts its positive inotropic action by direct stimulation of cardiac $\alpha$ and $\beta$ adrenoceptors. It has several theoretical advantages over dopamine: $(a)$ it has limited chronotropic effect; $(b)$ its use is not associated with an increase in systemic vascular resistance ${ }^{30} ;(c)$ it does not rely on release of endogenous catecholamines for any part of its action.

The dose of dobutamine that should be used is again unclear. Klarr et $a l^{35}$ and Roze et $a^{30}$ used doses of 5-20 $\mu \mathrm{g} / \mathrm{kg} /$ min, whereas Greenough ${ }^{36}$ used a maximum dose of $15 \mu \mathrm{g} /$ $\mathrm{kg} / \mathrm{min}$. Hentschel et al ${ }^{37}$ and Miall-Allen and Whitelaw ${ }^{38}$ both used a constant infusion rate of $10 \mu \mathrm{g} / \mathrm{kg} / \mathrm{min}$. Stopfkuchen $e t$ $a l^{39}$ showed a positive effect on left ventricular performance at doses of $7.5-10 \mu \mathrm{g} / \mathrm{kg} / \mathrm{min}$. The use of high doses $(>25 \mu \mathrm{g} /$ $\mathrm{kg} / \mathrm{min}$ ) has again not been studied.

There has been relatively little research into the use of dobutamine in preterm neonates, and it is generally used as a second line drug, in patients unresponsive to dopamine. However, several studies have compared dopamine with dobutamine in hypotensive preterm infants. A recent metaanalysis confirmed that dopamine is significantly more effective than dobutamine in the short term treatment of systemic hypotension in preterm infants. ${ }^{40}$ It also showed that there are fewer treatment failures with dopamine, but that there is no difference in the incidence of tachycardia between the two treatments. There were no differences in short term complications such as intraventricular haemorrhage and necrotising enterocolitis. No data are available on long term outcome for either drug.

\section{Other agents}

Most neonatal units advocate the use of adrenaline or noradrenaline in cases in which dopamine and dobutamine have failed to maintain "normal" blood pressure. However, very few studies have looked at the use of these agents in preterm infants. Seri and Evans ${ }^{41}$ have shown that the addition of adrenaline to dopamine increases both blood pressure and urine output in hypotensive neonates. Derleth ${ }^{42}$ has suggested that noradrenaline infusions are safe in neonates, and do not cause significant cerebral or myocardial vasoconstriction. Further research is clearly needed in this area before its routine use can be recommended.

Dopexamine, a relatively new synthetic catecholamine, has been shown to be effective in raising blood pressure and improving arterial $\mathrm{pH}$ and urine output. ${ }^{43}$ In neonates who are hypotensive secondary to septic shock, methylene blue, an inhibitor of soluble guanylate cyclase, has been shown to be effective in increasing blood pressure. ${ }^{44}$

\section{Steroids}

Antenatal steroids are now commonly given to mothers in preterm labour. They have been shown to have an independent effect (from the effect on respiratory distress syndrome) on reducing the incidence of hypotension in the preterm infant. ${ }^{45}$

In neonates with hypotension who are unresponsive to volume or pressor administration, there is growing evidence that steroids may be of some value. The theory is that infants with refractory hypotension may have relative adrenal insufficiency. ${ }^{34} 46-48$ Because glucocorticoids have a role in regulating the expression of cardiovascular adrenergic receptors, $^{33}$ this may render these infants incapable of responding to sympathomimetic agents.

$\mathrm{Ng}$ et $a l^{48}$ describe five VLBW infants with severe hypotension refractory to both volume expansion and inotropes. All the infants had a normal adrenocorticotrophic hormone response to human corticotrophin releasing hormone, but a low cortisol response, indicating adrenal insufficiency. Treatment with either single dose dexamethasone or a five day course of hydrocortisone was successful in all cases, with discontinuation of inotropes within 54 hours. None of the infants experienced further hypotensive episodes during the following week.

Bourchier and Weston ${ }^{49}$ found intravenous hydrocortisone, given as a reducing dose over a six day period, starting at $2.5 \mathrm{mg} / \mathrm{kg} / \mathrm{dose}$, to be as effective as dopamine in the treatment of hypotension in VLBW infants. Seri et al ${ }^{50}$ showed that hydrocortisone at $2-6 \mathrm{mg} / \mathrm{kg} /$ day resulted in a stable increase in mean blood pressure within six hours. Gaissmaier and Pohlandt ${ }^{51}$ carried out a double blind, placebo controlled study of the effects of single dose dexamethasone on preterm infants with refractory hypotension. They showed that a single dose of $250 \mu \mathrm{g} / \mathrm{kg}$ of dexamethasone is effective within 12 hours in improving severe arterial hypotension.

Some groups have advocated the use of hydrocortisone in smaller doses as prophylaxis against hypotension in at risk VLBW infants. ${ }^{52}$ Side effects from postnatal steroids are well documented and probably prohibit prophylactic use..$^{53}$

Based on the available evidence, we would advocate the use of a single dose of $250 \mu \mathrm{g} / \mathrm{kg}$ dexamethasone in babies with severe, intractable hypotension resistant to inotropes, with a further dose at 12 hours as rescue treatment in unresponsive cases. Although we recognise that there are significant concerns over the use of dexamethasone, it is not clear whether these concerns may in fact be related to any steroid. As the only randomised, blinded, placebo controlled 


Volume expansion $10-20 \mathrm{ml} / \mathrm{kg} 0.9 \%$ saline
1st line inotrope Dopamine $5-20 \mu \mathrm{g} / \mathrm{kg} / \mathrm{min}$
2nd line inotrope Dobutamine $5-20 \mu \mathrm{g} / \mathrm{kg} / \mathrm{min}$
Rescue therapy $250 \mu \mathrm{g} / \mathrm{kg}$ single dose

Figure 1 Flow chart for management of hypotension in the very low birthweight infant.

trial of steroids for hypotension uses dexamethasone, this would be our first choice over hydrocortisone. Obviously there is a balance of risks against benefits, but the short term benefit of preventing death must outweigh the long term risks, which are anyway unproven. Further research is obviously needed to decide the optimum dose and course. In our experience most babies do respond to one or occasionally two doses of dexamethasone.

\section{SUMMARY}

The management of hypotension in preterm infants remains controversial. Research in this area is relatively limited, which in part is probably due to the difficulty of obtaining continuous measures of tissue perfusion. There is no consensus on either the definition of hypotension or the level at which treatment should be initiated. The effects of aggressive correction are relatively underresearched, and there are few data on morbidity and mortality in relation to the use of volume support and inotropes. The aim of management must be to attain adequate tissue perfusion and oxygenation, but there may be little or no relation between blood pressure and organ perfusion. Further research is required into methods of assessing tissue perfusion, which can be used alongside monitoring of blood pressure to guide the neonatologist in deciding when to intervene.

Continuous invasive arterial blood monitoring remains the preferred method of recording blood pressure. Decisions to treat hypotension should be based on the general condition of the infant, not on the mean arterial blood pressure alone. On the basis of the available evidence, fig 1 outlines our view on the management of hypotension in the VLBW infant.

\section{Authors' affiliations}

S J Dasgupta, A B Gill, Peter Congdon Regional Neonatal Unit, Clarendon Wing, Leeds General Infirmary, Leeds Teaching Hospitals NHS Trust, Leeds LS2 9NS, UK

\section{REFERENCES}

1 Watkins AMC, West CR, Cooke RWI. Blood pressure and cerebral haemorrhage and ischaemia in VLBW infants. Early Hum Dev 1989:19:103-10.

2 Miall-Allen VM, De Vries LS, Whitelaw AGL. Mean arterial BP and neonatal cerebral lesions. Arch Dis Child 1987;62:1068-9.

3 Dammann O, Allred EN, Kuban KC, et al. Systemic hypotension and whitematter damage in preterm infants. Dev Med Child Neurol 2002;44:82-90.

4 Low JA, Froese AB, Galbraith RS, et al. The association between newborn hypotension and hypoxemia and outcome during the first year. Acta Paediatr 1993;82:433-7

5 Nuntnarumit P, Yang W, Bada-Ellzey HS. Blood pressure measurements in the newborn. Clin Perinatol 1999;26:981-96.
6 Lee J, Rajadurai VS, Tan KW. Blood pressure standards for very low birthweight infants during the first day of life. Arch Dis Child Fetal Neonatal Ed 1999;81:F168-70.

7 Hegyi T, Carbone MT, Anwar M, et al. Blood pressure ranges in premature infants. I. The first hours of life. J Pediatr 1994;124:627-33.

8 Hegyi T, Anwar M, Carbone MT, et al. Blood pressure ranges in premature infants. II. The first week of life. Pediatrics 1996;97:336-42.

9 Kimble KJ, Darnall RA, Yelderman MD. An automated technique for estimating mean arterial pressure in critically ill newborns. Anesthesiology 1981;54:423-5.

10 Dellagramaticas HD, Wilson AJ. Clinical evaluation of the Dinamap noninvasive blood pressure monitor in pre-term neonates. Clin Phys Physiol Meas 1981;2:271-6.

11 Diprose GK, Evans DH, Archer LNJ, et al. Dinamap fails to detect hypotension in very low birthweight infants. Arch Dis Child 1986;61:771-3.

12 Weindling AM. Blood pressure monitoring in the newborn. Arch Dis Child 1989:64:444-7.

13 Kluckow M, Evans N. Relationship between blood pressure and cardiac output in preterm infants requiring mechanical ventilation. J Pediatr 1996; 129:506-12.

14 Kluckow M, Evans N. Superior vena cava flow in newborn infants: a novel marker of systemic blood flow. Arch Dis Child Fetal Neonatal Ed 2000;82:F182-7.

15 Wardle SP, Yoxall CW, Weindling AM. Peripheral oxygenation in hypotensive preterm babies. Pediatr Res 1999:45:343-9.

16 Tsuji M, Saul JP, du Plessis A, et al. Cerebral intravascular oxygenation correlates with mean arterial pressure in critically ill premature infants. Pediatrics 2000; 106:625-32.

17 Wardle SP, Yoxall CW, Weindling AM. Determinants of cerebral fractional oxygen extraction using near infrared spectroscopy in preterm neonates. $J$ Cereb Blood Flow Metab 2000;20:272-9.

18 Campbell ME, Van Aerde JE, Cheung Po-Yin, et al. Tonometry to estimate intestinal perfusion in newborn piglets. Arch Dis Child Fetal Neonatal Ed 1999:81:F105-9.

19 Campbell ME, Costeloe KL. Measuring intramucosal pH in very low birth weight infants. Pediatr Res 2001;50:398-404

20 Raja NV, Maisels M, Kring ERN, et al. Capillary refill time in the hands and feet of normal newborn infants. Clin Pediatr 1999; 38:139-44.

21 Tibby SM, Hatherill M, Murdoch IA. Capillary refill time and core-peripheral temperature gap as indicators of haemodynamic status in pediatric intensive care patients. Arch Dis Child 1999;80:163-6.

22 Panerai RB, Kelsall AWR, Rennie JM, et al. Cerebral autoregulation dynamics in premature newborns. Stroke 1995;26:74-80.

23 Pryds O, Edwards AD. Cerebral blood flow in the newborn infant. Arch Dis Child Fetal Neonatal Ed 1996;74:F63-9.

24 Gill $A B$, Weindling AM. Cardiac function in the shocked very low birthweight infant. Arch Dis Child 1993:6817-21.

25 Dimitriou G, Greenough A, Mantagos J, et al. Metabolic acidosis, coreperipheral temperature difference and blood pressure response to albumin infusion in hypotensive, very premature infants. J Perinat Med 2001;29:442-5.

26 Emery EF, Greenough A, Gamsu HR. Randomised controlled trial of colloid infusions in hypotensive preterm infants. Arch Dis Child 1992;67:1185-8.

27 King W SO, Tai F Fok, Pak C Ng, et al. Randomised controlled trial of colloid or crystalloid in hypotensive preterm infants. Arch Dis Child Fetal Neonatal Ed 1997;76:F43-6.

28 Gill $A B$, Weindling AM. Randomised controlled trial of plasma protein fraction versus dopamine in hypotensive very low birth weight infants. Arch Dis Child 1993:69:284-7.

29 Seri I. Cardiovascular, renal, and endocrine actions of dopamine in neonates and children. J Pediatr 1995;126:333-44.

30 Roze JC, Tohier C, Maingueneau C, et al. Response to dobutamine and dopamine in the hypotensive very preterm infant. Arch Dis Child 1993;69:59-63.

31 Padbury JF, Agata Y, Baylen BG, et al. Dopamine pharmacokinetics in critically ill newborn infants. J Pediatr 1986;110:293-8.

32 Seri I, Abbasi S, Wood D, Gerdes JS. Regional hemodynamic effects of dopamine in the sick preterm neonate. J Pediatr 1998; 133:728-34.

33 Hausdorff WP, Caron MG, Lefkowitz RJ. Turning off the signal: desensitization of $\beta$-adrenergic receptors. FASEB J 1990:4:33-40.

34 Scott SM; Watterberg KL. Effect of gestational age, postnatal age, and illness on plasma cortisol concentrations in premature infants. Pediatr Res 1995;37:112-16

35 Klarr JM, Faix RG, Pryce CJE, et al. Randomized, blind trial of dopamine versus dobutamine for treatment of hypotension in preterm infants with respiratory distress syndrome. J Pediatr 1994; 125:117-22.

36 Greenough A, Emery EF. Randomized trial comparing dopamine and dobutamine in preterm infants. Eur J Pediatr 1993:152:164-5.

37 Hentschel R, Hensel D, Brune T, et al. Impact on blood pressure and intestinal perfusion of dobutamine or dopamine in hypotensive preterm infants. Biol Neonate 1995;68:318-24.

38 Miall-Allen VM, Whitelaw AGL. Response to dopamine and dobutamine in the preterm infant less than 30 weeks gestation. Crit Care Med 1989;17:1166-9

39 Stopfkuchen H, Queisser-Luft A, Vogel K. Cardiovascular response to dobutamine determined by systolic time intervals in preterm infants. Crit Care Med 1990; 18:722-4. 
40 Subedhar NV, Shaw NJ. Dopamine versus dobutamine for hypotensive preterm neonates. Cochrane Database Systemat Rev 2000;2:CD001 242.

41 Seri I, Evans J. Addition of epinephrine to dopamine increases blood pressure and urine output in critically ill extremely low birthweight neonates with uncompensated shock. Pediatr Res 1998:43(suppl 2):194.

42 Derleth DP. Clinical experience with norepinephrine infusions in critically ill newborns. Pediatr Res 1997;41:145.

43 Kawczynski P, Piotrowski A. Circulatory and diuretic effects of dopexamine infusion in low-birth-weight infants with respiratory failure. Intensive Care Med 1996:22:65-70.

44 Driscoll W, Thurin S, Carrion V, et al. Effect of methylene blue on refractory neonatal hypotension. J Pediatr 1996; 129:904-8.

45 Moise AA, Wearden ME, Kozinetz CA, et al. Antenatal steroids are associated with less need for blood pressure support in extremely preterm infants. Paediatrics 1995;95:845-50.

46 Tantivit P, Subramanian N, Garg M, et al. Low serum cortisol in term newborns with refractory hypotension. J Perinatol 1999;19:352-7.
47 Heckmann M, Wudy SA, Haack D, et al. Serum cortisol concentrations in ill preterm infants less than 30 weeks gestational age. Acta Paediatr 2000;89:1098-103

$48 \mathrm{Ng} \mathrm{PC}$, Lam CWK, Fok TF, et al. Refractory hypotension in preterm infants with adrenocortical insufficiency. Arch Dis Child Fetal Neonatal Ed 2001;84:F122-4.

49 Bourchier D, Weston PJ. Randomised trial of dopamine compared with hydrocortisone for the treatment of hypotensive very low birth weight infants. Arch Dis Child Fetal Neonatal Ed 1997:76:F174-8.

50 Seri I, Tan R, Evans J. Cardiovascular effects of hydrocortisone in preterm infants with pressor-resistant hypotension. Pediatrics 2001;107:1070-4.

51 Gaissmaier RE, Pohlandt F. Single-dose dexamethasone treatment of hypotension in preterm infants. J Pediatr 1999;134:701-5.

52 Rajah V. Treatment of hypotension in very low birthweight infants [letter]. Arch Dis Child Fetal Neonatal Ed 1998;78:F156.

53 Sweet DG, Halliday HL. A risk-benefit assessment of drugs used for neonatal chronic lung disease. Drug Safety 2000;22:389-404.

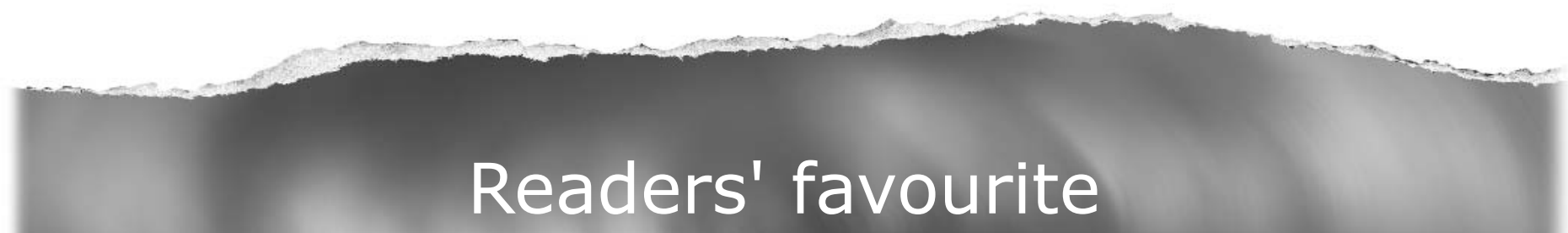

\section{Top 10}

Click on the "Top 10" button on the homepage to see which are the best read articles each month

www.archdischild.com 